\title{
Design and Implementation of College Sports Management Information System based on UML
}

\author{
ZHANG Shu-An ${ }^{1, a}$ \\ ${ }^{1}$ Pingdingshan Industrial College of Technology, Pingdingshan, Henan 467001, China \\ azhangshuan@126.com
}

Keywords: UML; Sports management information system; System design

\begin{abstract}
This paper used the methods like literature data method to analyze the present situation of university sports information management, expound college PE informationization goal, and use UML to conduct university sports information management system function analysis and design from the perspective of system development. Detailed description of the system module partition and the implementation process is explained in order to provide help for the college sports information management.
\end{abstract}

\section{Introduction}

With the expansion of colleges and universities, offices and campus increases and spread our, which add the difficulty for the management of college sports. So step up the pace of the university sports information construction, and eventually improve the level of sports teaching quality and teaching mainly lies in strengthening the construction of informatization. Embarks from the actual situation, this article analyzed and built a general college sports management information system. UML is used for the design of the system in detail.

\section{Analysis of the college sports management information system needs}

\section{Management status of college sports information}

As for the management of college sports, it has the same aspects with other teaching department, at the same time it also has its own uniqueness and complexity. It is showed by the fact that it have both the closure of the teachers' information management and openness of student sports information management; the elements of management of teachers, students and others, and management on the elements of the venues, equipment, etc. [1]The uniqueness and complexity of objective existence, plus the lack of sports information talents in universities and colleges, makes the college sports management informatization and automation level significantly lower. Sports management mode is mainly artificial management, but as the surge in management information, it makes the disadvantage of this approach more and more obvious, which is mainly showed in the following aspects: (1) college sports information infrastructure construction is in the low level and infrastructure construction is not balanced; (2) data storing is scattered, messy, management ration low, information resource conservation time too short, the informatization is in a serious shortage of human resources reserves; (3) information collection and management way is backward, management in low efficiency.

\section{Goal of college PE informationization}

Sports information of institutions of higher learning means to apply modern information technology in the high school physical education system in full integration to realize of digitization, networking, and virtualization of physical education teaching, sports organization and management, the campus sports culture activities to a certain extent, so as to improve the education quality and efficiency, and finally formed colleges and universities sports education new mode adapt to the requirements of the information society. The development of college sports management information system will help to carry on the scientific management of the various business processes of college sports, which is conducive to complete various functions and objectives of the college sports. [2] The construction of college sports management information system is put forward 
under this premise.

\section{Analysis and design of college sports information management system}

\section{Goal of the system}

With the further development of college PE teaching reform, teaching content and teaching method is diversified. With the increasing enrollment of regular institutions of higher learning at the same time, all kinds of information need to deal with about the students is more and more, the traditional manual management way already can not adapt to the requirements of modern management, make the service function of physical education play limited. The construction of college sports information management system has become the urgent matter. [3] College sports information management system is mainly to build a integrated information management system including sports management, sports facilities, sports teaching, sports scientific research management and books information management to provide decision support for school sports development, meet the needs of the university sports daily management, improve the quality of college sports management, and enhance the level of university sports scientific research for the need of information explosion and modern management.

\section{Analysis of system function}

With the vigorous development of undertakings of physical culture and sports in colleges and universities, many colleges and universities have their own sports institute, even colleges with no sports institute has basically established a dedicated sports education in school. As an independent department, college sports management can involve in a lot of work. And relative to other teaching department, sports management include the venue, facilities maintenance and management, which increased the complexity and difficulty of sports management, so the construction of college sports constantly improving management information system is a system engineering. In the analysis of system function, we must grasp the whole, subdivide the process step by step.

System use case diagram is the external characterization system view, which a complete the system provided for a one or a few actors. It is mainly used to describe the demand of the users and management personnel, namely some action users and managers want system has that can complete certain function. So create and explains the use case diagram according to the needs of users and administrators to describe what function the software should have and the relationship between these functions is the starting point of design system analysis phase. [4]Case diagram contains use cases and participants, cases associated with connection between each other in order to reflect the system of the whole structure and function to the user, the insufficiency of the system can be seen clearly, provide basis for managers and users to better understand the system function, also can let users better, management personnel involved in to improve the system function.

\section{Module partition of system}

Development and design of system must involve in the participation of users. According to the use case diagram, the sports management demands for the function of school physical education management information system, we may safely draw the system module partition of the graph, the module partition graph is shown in the figure below: 


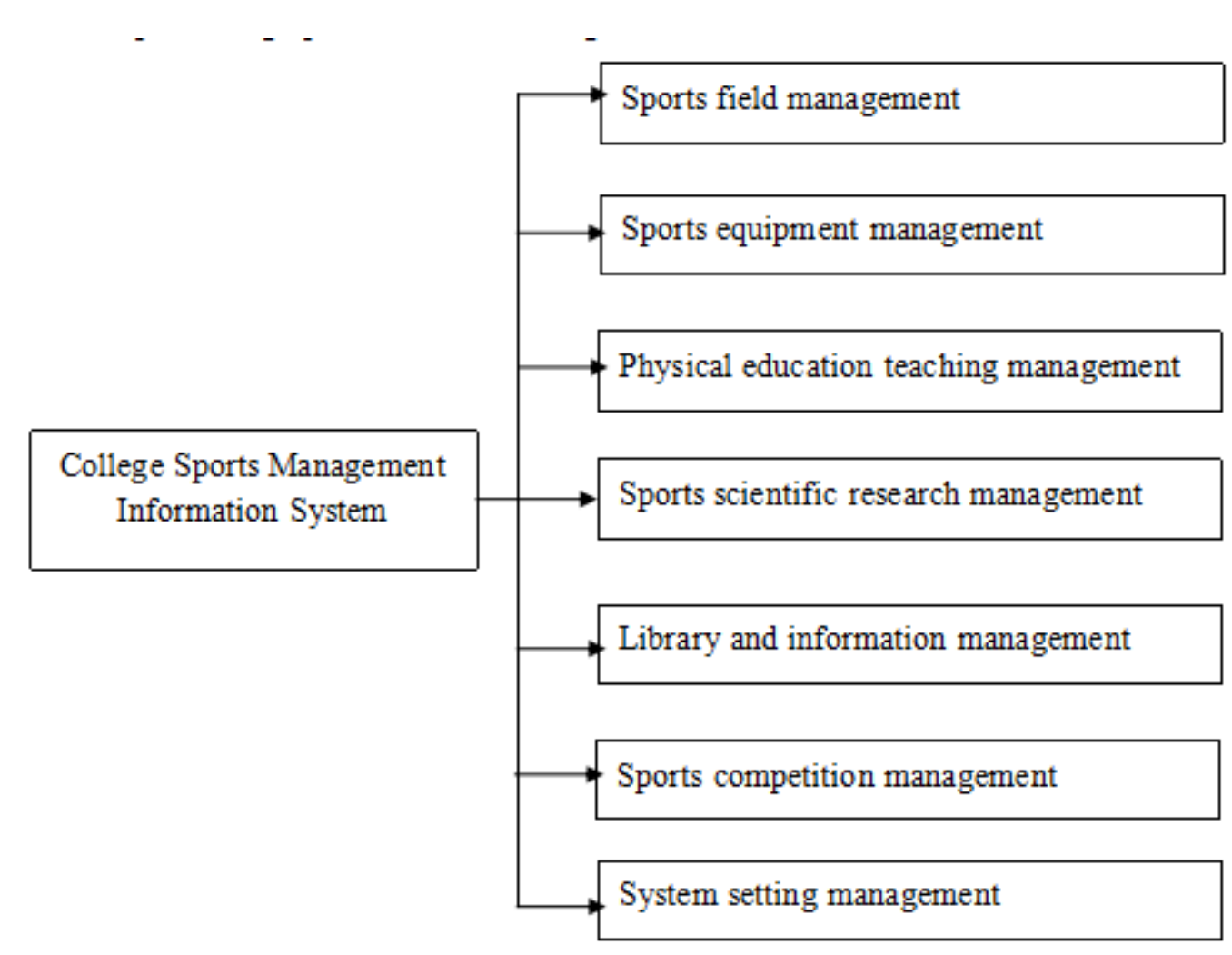

Figure 1 College sports management system module partition

From the figure above it can be concluded that the system is divided into sports venue management, equipment management, sports teaching management, scientific research and management, books management, sports competition management and system management module.

(1) sports site management module includes basic information management, sports venues venues add, maintenance, application and auditing, and other functions, including sports venues usage report review and analysis.

(2) sports equipment management module includes school sports equipment, facilities purchase, register, allocation and inventory management, etc. [5]Through the system function module can realize the control of school sports equipment to conduct scientific management and distribution for the school sports facilities, equipment and can effectively control the sports facilities equipment, avoiding erosion.

(3) sports teaching management module includes students' course selection, students' achievement inquiry, teachers' archives management, attendance of teaching, teaching evaluation, student information management, and other functions. This part mainly aims at the school sports teaching work, which can effectively arouse the enthusiasm of physical education teachers in colleges and universities, and also convenient for the student's online courses and query performance in a timely manner.

(4) sports scientific research management module is mainly geared to the needs of teachers, the sports teacher's scientific research and subject to entry registration and management. Scientific research achievements include the author, publications, published time, name of magazine, which is advantageous to the query and reference when necessary.

(5) books and materials management module of function is close with the library's system, mainly used for management of college sports resources library borrowing.

(6) sports competition management module is mainly responsible for high level athlete's basic information and the results obtained by high level athletes race management and statistics. The child module is mainly to complete inputting statistics, inquiry and related form generation of the basic information such as athlete's name, student number, gender, date of birth, and special projects of the high level athletes and competition performance.

(6) system settings management module mainly includes issue of the user name and password to 
the administrators at all levels, teachers permissions modify, system style settings and system initialization.

\section{Sequence diagram of system}

The logic of the sequence diagram is for system modeling, it is almost a self-describing. It shows the relationship between different objects in the process of the invocation, at the same time it can also display different calls to different objects in a very detailed way. The main purpose of the sequence diagram is to define the sequence of events, produce some output of hope. The point is not the message itself, but the message of the order. However, most of the sequence diagram shows what message passed between system object, and the order they happen. According to the information of horizontal and vertical dimensions: the vertical dimension show message call from top to bottom of time series, dimension level the object instance from left to right message sent to. Between six modules in this system, it follow the principle of "high cohesion and low coupling" to design, each module being subsystem between each other with less contact. Here take the sports venue management module sequence diagrams as example. The sequence diagram describes the main process of a sports venue management module, mainly describes the administrator system, sports ground, sports ground change management information, which can then be applied to sports management center for sports ground by the user, the user can include teachers, students are also included, then reply to the applicant after checking by the administrator.

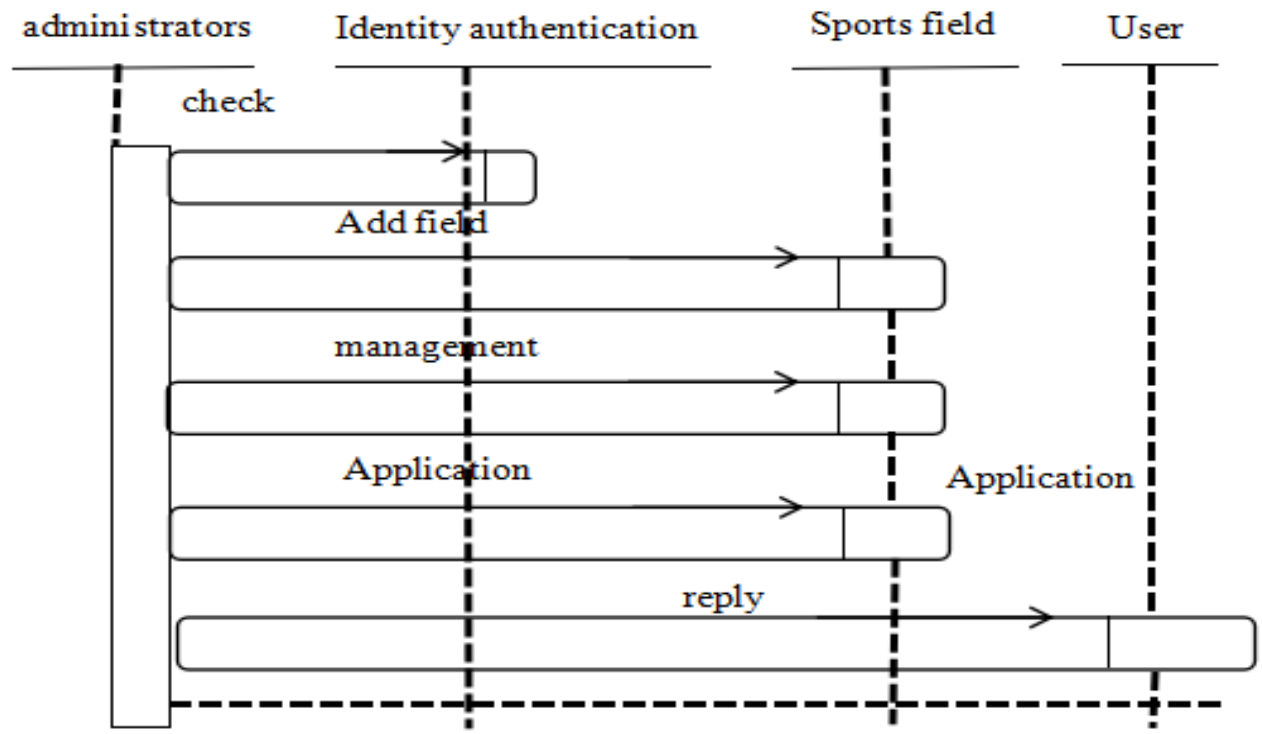

Figure2. Sports site managem ent module sequence diagram

\section{System implementation}

\section{System development platform}

College sports management information system development platform recommended Linux operating system, database system uses the MYSQL database, programming language uses PHP and javaScript language, Web server uses Apavhe Web server. Because all these technology has the characteristics of being free with open source, powerful, and integrated with each other. In the same time of reducing the development costs, the Linux operating system has the advantages of high stability, avoid from the virus than Windows .

\section{System deployment figure}

The deployment of the college sports management information system is a complex project. If connect the system with the campus network, then as long as you can connect the campus network, users can access to sports management information system and check the required information in time. Also if let outside users access through the Internet, we can release the system to the Web application server. In order to ensure data security and confidentiality, all the data is deployed to the 
database server, then external users can only send request to the Web application server and the Web application server access the database server. Build a firewall between the Web application server and the user also has provided the safeguard for the normal operation of the system.

\section{Summary}

College sports information management system is a large and complex system involving a lot of factors. Due to the constant reform of the college sports, college sports information management system is featured by being dynamic and changeable, which makes it hard to form a clear understanding of the teaching system. Therefore, it can effectively improve the quality and efficiency of college sports management by developing sports information management system with the aid of the characteristics of high efficiency, high speed and large capacity of computer system. Scientific management, in turn, can save the cost of sports management and implementation. Information management system is man-machine system made up of people and computer. In the improvement of the system and successful application, we should not only consider the technical question, what is more important to consider is organizational processes and behavior, which is also direction we need to work to in the future.

\section{References}

[1] Xiao Hong, Xiao Jingbo. Push service in university library system based on RSS [J]. The design and implementation of intelligence journal. 2009 (3): 11-15

[2] Kong Jun, Yi Qin. College sports management information system based on C/S and B/S [J]. Journal of Wuhan sports college journal. 2007 (10): 65-68

[3] Chang Dongdong. Study on the model of school physical education in colleges and universities information management [J]. Journal of Hubei sports science. 2007 (5): 30-32

[4] Zhang Chunfang. The development of information technology and sports education [J]. Journal of Wuhan sports college journal. 2004 (6): 11-12

[5] Job M.Carroll, Marry Beth Rosson, George Chin Jr, Jurgen Koenemann. Requirements Development in Seenario-based design[J]. IEEE Trans on Soft Eng, 1998,1156-1169 